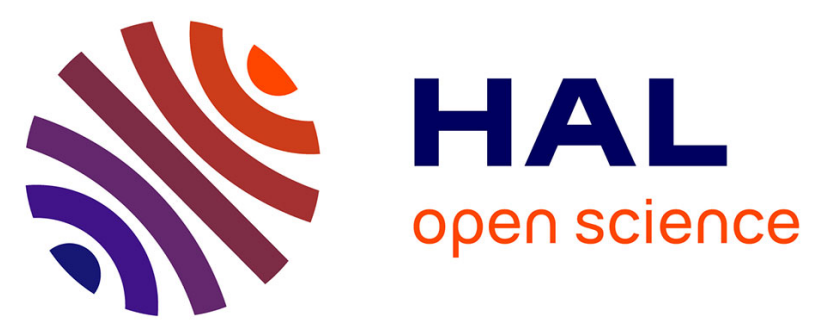

\title{
Multispecies transmitter for DIAL sensing of atmospheric water vapour, methane and carbon dioxide in the $2 \mu \mathrm{m}$ region
}

Dominique Mammez, Erwan Cadiou, Jean-Baptiste Dherbecourt, Myriam Raybaut, Jean-Michel Melkonian, Antoine Godard, Guillaume Gorju, Jacques Pelon, Michel Lefebvre

\section{To cite this version:}

Dominique Mammez, Erwan Cadiou, Jean-Baptiste Dherbecourt, Myriam Raybaut, Jean-Michel Melkonian, et al.. Multispecies transmitter for DIAL sensing of atmospheric water vapour, methane and carbon dioxide in the $2 \mu \mathrm{m}$ region. Lidar Technologies, Techniques, and Measurements for Atmospheric Remote Sensing XI, SPIE, Sep 2015, Toulouse, France. pp.964507, 10.1117/12.2194754 . insu-01216819

\section{HAL Id: insu-01216819 \\ https://hal-insu.archives-ouvertes.fr/insu-01216819}

Submitted on 14 Jan 2022

HAL is a multi-disciplinary open access archive for the deposit and dissemination of scientific research documents, whether they are published or not. The documents may come from teaching and research institutions in France or abroad, or from public or private research centers.
L'archive ouverte pluridisciplinaire HAL, est destinée au dépôt et à la diffusion de documents scientifiques de niveau recherche, publiés ou non, émanant des établissements d'enseignement et de recherche français ou étrangers, des laboratoires publics ou privés.

\section{(ㅇ)(1) $\$$}

Distributed under a Creative Commons Attribution - NonCommerciall 4.0 International 


\title{
Multispecies transmitter for DIAL sensing of atmospheric water vapour, methane and carbon dioxide in the $2 \mu \mathrm{m}$ region Dominique Mammez ${ }^{\mathrm{a}, \mathrm{b}}$, Erwan Cadiou ${ }^{\mathrm{a}}$, Jean-Baptiste Dherbecourt ${ }^{\mathrm{a}^{*}}$, Myriam Raybaut ${ }^{\mathrm{a}}$, Jean- Michel Melkonian ${ }^{\mathrm{a}}$, Antoine Godard ${ }^{\mathrm{a}}$, Guillaume Gorju ${ }^{\mathrm{a}}$, Jacques Pelon $^{\mathrm{c}}$, Michel Lefebvre ${ }^{\mathrm{a}}$ ${ }^{a}$ ONERA-The French Aerospace Lab, BP 80100, F-91123 Palaiseau cedex, France; ${ }^{\mathrm{b}}$ CNES, centre de Toulouse, 18 avenue Edouard Belin, F-31401 Toulouse cedex 9, France; ${ }^{\mathrm{c}}$ LATMOS, Université Pierre et Marie Curie, 4 Place Jussieu, F-75005 Paris, France.
}

\begin{abstract}
Integrated-path differential absorption lidar (IPDIAL) is an attractive technique to monitor greenhouse gases from space. For that purpose, suitable absorption lines have been identified as good candidates around $2.05 \mu \mathrm{m}$ for $\mathrm{CO}_{2}, 2.29 \mu \mathrm{m}$ for $\mathrm{CH}_{4}$, and $2.06 \mu \mathrm{m}$ for $\mathrm{H}_{2} \mathrm{O}$. In this context, we have developed a high energy transmitter around $2 \mu \mathrm{m}$ based on frequency conversion in a nested cavity doubly resonant optical parametric oscillator (NesCOPO) followed by high energy parametric amplification. This master oscillator power amplifier (MOPA) architecture enables the generation of tunable single-frequency high energy nanosecond pulses (tens of $\mathrm{mJ}$ ) suitable for atmospheric DIAL applications. Moreover, taking advantage of the wide spectral coverage capability of the NesCOPO, we demonstrate the potential for this single emitter to address the aforementioned spectral lines, without the use of additional seeding devices. The emitter provides energies up to $20 \mathrm{~mJ}$ for the signal waves in the vicinity of $\mathrm{CO}_{2}$ and $\mathrm{H}_{2} \mathrm{O}$ lines, and $16 \mathrm{~mJ}$ at $2290 \mathrm{~nm}$ for the $\mathrm{CH}_{4}$ line. By implementing a control loop based on a wavemeter frequency measurement, the signal fluctuations can be maintained below $1 \mathrm{MHz}$ rms for $10 \mathrm{~s}$ averaging time. Finally, from optical heterodyne analysis of the beat note between our emitter and a stabilized laser diode, the optical parametric source linewidth was estimated to be better than $60 \mathrm{MHz}$ (Full width at half maximum).
\end{abstract}

Keywords: Lidar, DIAL, Emitter, OPO, Greenhouse Gases

\section{INTRODUCTION}

Integrated-path differential absorption lidar (IPDIAL) remote sensing of greenhouse gases from space is a promising way to retrieve and monitor the mixing ratios of the main greenhouses gases. In such a context, there is a strong need for high energy, nanosecond single frequency mid-infrared sources. Moreover, the spatial, temporal, and spectral properties of the radiation used for such probing are critical to achieve a high sensitivity measurement with a good spatial resolution. Indeed, taking into account the overall instrument error budget for such spaceborne measurements, very demanding specifications are expected for the emitter, in terms of emitted wavelength, output energy, frequency stability and beam quality ${ }^{1,2}$.

For example, in the case of $\mathrm{CO}_{2}$, which is one of the main specie of interest, the $\mathrm{R} 30$ absorption line around $2 \mu \mathrm{m}$ can be selected to optimize the IPDIAL measurement, while minimizing the effect of water vapour interferences ${ }^{1}$. In this case, the frequency of the emitter has to be tuned a few $\mathrm{GHz}$ apart from the line center to optimize the absorption depth, with a frequency locking stability better than $1 \mathrm{MHz}$ rms over $10 \mathrm{~s}$. These challenging spectral properties are required to measure the ground-level $\mathrm{CO}_{2}$ distribution with an expected $0.4 \%$ accuracy, while avoiding the detrimental effects of water vapour and atmospheric temperature variations.

Several emitter architectures were proposed to fulfill such stringent specifications. In most of the cases, these architectures rely on the use of several additional injection seeding sources, to generate the different "On" and "Off" wavelengths needed to perform a DIAL measurement. Injection seeded laser oscillators at $2.05 \mu \mathrm{m}$ for $\mathrm{CO}_{2}$ monitoring ${ }^{1,3,4}$ or injection seeded optical parametric oscillators (OPO) emitting around 1.57 and $1.6 \mu \mathrm{m}$, for $\mathrm{CO}_{2}$ or $\mathrm{CH}_{4}$ monitoring respectively ${ }^{5,6,7,8,9}$ have thus been developed. Given the reduced tuning capability of the seeders, these systems were mainly developed using an emitter per gas target species. Indeed, the tuning capability of the source depends on the availability and tuning properties of the seeding device. Moreover, when multi-wavelength DIAL or multispecies DIAL operation is desired, this arrangement implies at least one seeder per emitted wavelength to enable 
fast, shot by shot, wavelength switching, while maintaining stable and reproducible single frequency operation at each wavelength. Such an approach can thus lead to complex systems.

In this a context, no demonstration of a generic emitter approach, allowing targeting the three main species of interest $\left(\mathrm{CO}_{2}, \mathrm{CH}_{4}\right.$ and $\left.\mathrm{H}_{2} \mathrm{O}\right)$ for IPDIAL sensing from space with a single device, was reported so far.

To be able to develop a truly generic emitter for multi-species gas probing, we propose the development of a parametric optical source, based on a specific OPO cavity, allowing single frequency emission in the pulsed regime without the need of an additional seeding source. The idea is to develop an emitter capable of probing all the three main species of interest $\left(\mathrm{CO}_{2}, \mathrm{CH}_{4}\right.$ and $\left.\mathrm{H}_{2} \mathrm{O}\right)$, leading to the possibility of i) a single payload development process for several instruments dedicated to different gas probing missions, thus reducing costs and risks, ii) missions based on a single emitter for multispecies probing, iii) in orbit reconfiguration of the mission to change the target gas.

To achieve this goal, we have designed and patented a specific frequency agile OPO: the nested cavity OPO (NesCOPO) device. Due to its doubly-resonant nested cavity configuration, it can produce nanosecond, widely tunable, single frequency pulses in the mid-infrared range, without the need for an additional injection seeding source ${ }^{10}$. This new OPO architecture enables to carry out continuous tuning as well as mode-hop tuning using the so-called Vernier frequency sampling technique, as we previously demonstrated ${ }^{11}$. This tuning method, specific to the NesCOPO scheme, enables to generate sequences of wavelengths where both frequency resolution and span are separately adjustable and can be tailored to fulfill the requirements either for broadband spectroscopy ( $>50 \mathrm{~cm}^{-1}$ spectral coverage) at low resolution or for high resolution $\left(<0.01 \mathrm{~cm}^{-1}\right)$ narrow band spectroscopy. It is thus possible to produce sequences of wavelengths necessary for DIAL applications, with a single NesCOPO device, over several hundreds of nanometers, thus covering several species of interest.

To demonstrate its potential for IPDIAL applications, NesCOPO devices were implemented as emitters for short range (> $30 \mathrm{~m}$ ) atmospheric $\mathrm{CO}_{2}$ measurements at $4.2 \mu \mathrm{m}^{11}$ and simultaneous $\mathrm{H}_{2} \mathrm{O}$ and $\mathrm{CH}_{4}$ IPDIAL measurement around $3.3 \mu \mathrm{m}^{12}$.

Also, to assess the potential of the NesCOPO for single species $\left(\mathrm{CO}_{2}\right)$ remote and range resolved sensing from space, we previously developed a high-energy, high-beam-quality nanosecond master oscillator-power amplifier (MOPA) parametric source emitting up to $10 \mathrm{~mJ}$ in coincidence with the $2.051 \mu \mathrm{m} \mathrm{CO}_{2} \operatorname{line}^{13}$.

Here, taking advantage of the wide spectral coverage capability of the NesCOPO architecture and the fact that the OPO concept allows the generation of two waves (signal and idler), we demonstrate the first three-species emitter in the $2 \mu \mathrm{m}$ range able to reach the absorption lines of the three main greenhouse gases. This single emitter is capable of monitoring $\mathrm{CO}_{2}, \mathrm{CH}_{4}$ and $\mathrm{H}_{2} \mathrm{O}$ using the spectral lines at $2.05 \mu \mathrm{m}, 2.29 \mu \mathrm{m}$ and $2.06 \mu \mathrm{m}$, respectively ${ }^{1}$.

\section{EXPERIMENTAL SETUP}

Our experimental setup consists of a MOPA configuration, as depicted in Figure 1. It is based on three main devices: i) a commercial pump laser, ii) the NesCOPO oscillator producing a single-frequency, high-purity and high-beam-quality radiation, and iii) the parametric amplifier based on different high-aperture nonlinear crystals, specifically designed to ensure a high amplification towards the multi-millijoule level, while maintaining the spectral and spatial properties of the oscillator radiation.

The pump laser is a commercial $100 \mathrm{~mJ}$ Nd:YAG laser, injection seeded by a CW ytterbium-doped fiber laser, and delivering $12 \mathrm{~ns}$ long pulses at a $30 \mathrm{~Hz}$ repetition rate. Single frequency emission of the pump is servo-controlled by the build-up time minimization method.

The NesCOPO master oscillator is based on a narrow-gain-bandwidth type-II periodically poled lithium niobate (MgO:PPLN) nonlinear crystal (HC Photonics). Several crystal lengths from $7 \mathrm{~mm}$ to $16 \mathrm{~mm}$ can be implemented, leading to different signal cavity free-spectral range in the few GHz range. The two mirrors of the signal cavity (M1M3) are highly reflective while the idler cavity consists of the highly reflective mirror (M3) and an output coupler (M2, $\mathrm{R}=80 \%$ ). M3 also ensures double pump pass, thus reducing the OPO threshold. The NesCOPO threshold is indeed bellow $200 \mu \mathrm{J}$, and pumped by up to $500 \mu \mathrm{J}$ emits up to $30 \mu \mathrm{J}$ of idler to be further amplified. Single frequency operation of the device is obtained with an appropriate dissociation of the two cavity lengths of the NesCOPO device ${ }^{10}$, leading to a single pair of signal and idler cavity modes whose frequencies can satisfy the three-wave-mixing energy conservation in the parametric gain bandwidth. Tunability of the NesCOPO can be achieved by i) translation of the crystal to target different poling periods of the PPLN, leading to several tens of nanometers of tuning, ii) temperature tuning on a given 
poling period $\left(0.9 \mathrm{~nm} /{ }^{\circ} \mathrm{C}\right.$ close to degeneracy), iii) fine frequency tuning over a few nanometers, with a high precision $(\mathrm{MHz})$, moving mirrors M2 and M3 (mounted on piezoelectric transducers) to adjust the signal and idler cavity lengths.

Amplification is then realized in a multi-stage amplifier architecture. A preamplifier stage, with a gain factor of 40 , pumped by pulses of $\sim 3 \mathrm{~mJ}$ at $1064 \mathrm{~nm}$, is first implemented. It is composed of a single 25-mm-long, 2-mm-thick, type$0 \mathrm{MgO}: \mathrm{PPLN}$ crystal (provided by HC Photonics). At the output of the preamplifier, the idler beam is filtered out and the signal beam is adapted to match the pump beam size in the following stages. A high energy amplifier then amplifies the signal wave to an energy level of $20 \mathrm{~mJ}$, when pumped by $90 \mathrm{~mJ}$ of incident pump. It is composed of three 25 -mm-long bulk KTP crystals and an additional 20-mm-long bulk KTP crystal (crystals provided by Cristal Laser). To maintain the spatial beam quality, the KTP crystals are mounted in the walk-off compensation configuration. Moreover, to prevent back conversion, the idler wave can be filtered out between the last two crystals. Furthermore, a $10 \mathrm{~ns}$ delay line is inserted in the pump path just before amplification so as to compensate for the OPO build-up time.

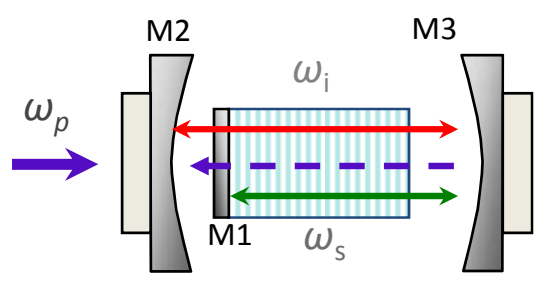

(a)

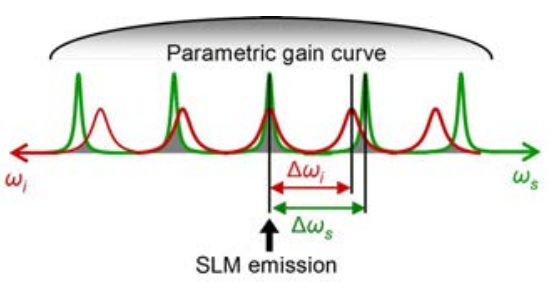

(b)

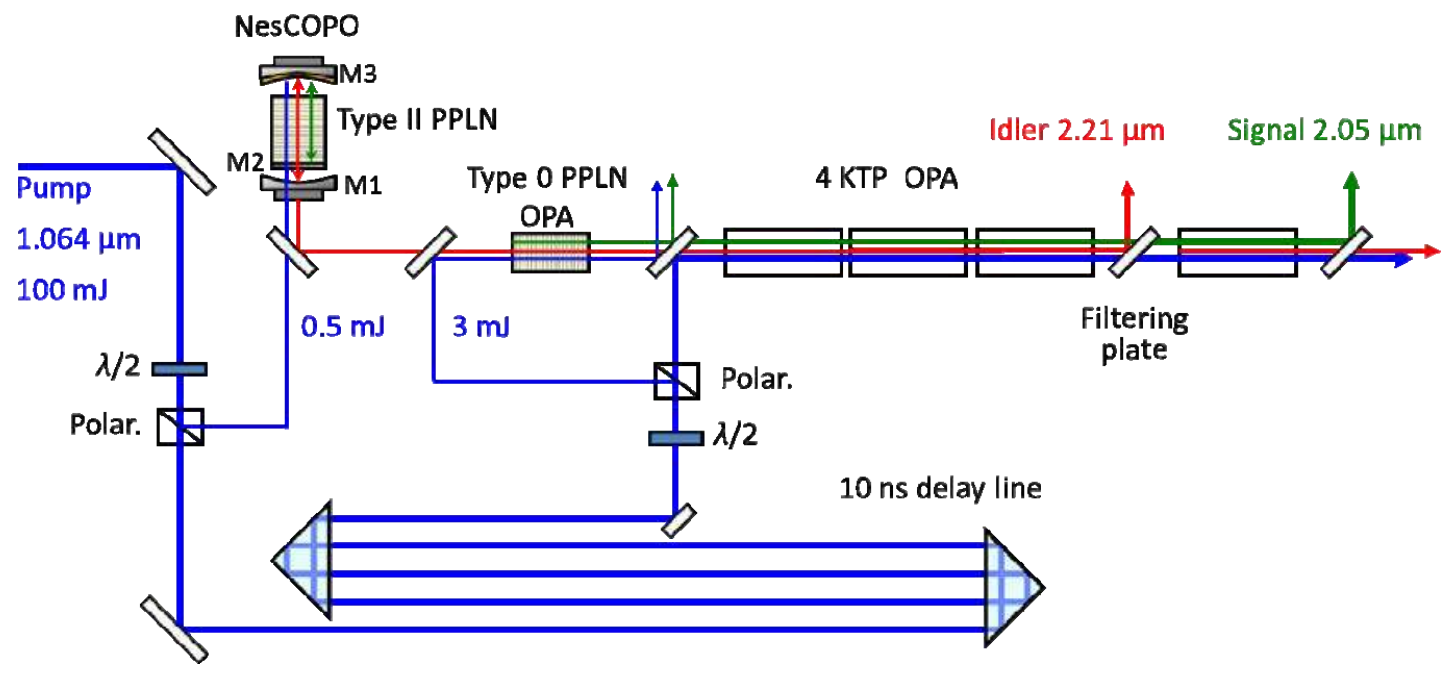

(c)

Figure 1. NesCOPO design (a), Illustration of the mode selection based on the Vernier effect: a single pair of NesCOPO signal and idler modes correctly overlap (b), Schematic diagram of the MOPA overall design (c).

\section{EMITTER TUNABILITY AND PULSE ENERGY PERFORMANCES}

The pulse energies, spatial beam-quality and spectral performances are measured at the output of the amplification stages.

First, we investigate the tuning capability of the emitter. Figure 2 presents the spectral coverage of this optical source, by temperature tuning, for two different quasi-phase matching (QPM) grating periods of the NesCOPO type II PPLN 
crystal. We also display the absorption lines of different gas species, calculated using Hitran 2012 database, to show how this emitter can target i) different species of interest, ii) different absorption lines for each species.

Indeed, with the QPM period of $14.369 \mu \mathrm{m}$, the $\mathrm{CO}_{2}(2.051 \mu \mathrm{m})$, and $\mathrm{H}_{2} \mathrm{O}(2.056 \mu \mathrm{m})$ absorption lines can be targeted, with a temperature variation of only $6{ }^{\circ} \mathrm{C}$. Moreover, a $\mathrm{CH}_{4}$ absorption line at $2.21 \mu \mathrm{m}$ can also be addressed with the same grating period with the idler wave.

The $\mathrm{CH}_{4}$ line of interest for space remote sensing at $2.29 \mu \mathrm{m}$ can be addressed by translating the PPLN crystal to use a second QPM period of $14.38 \mu \mathrm{m}$ and tuning the temperature (Figure 2).
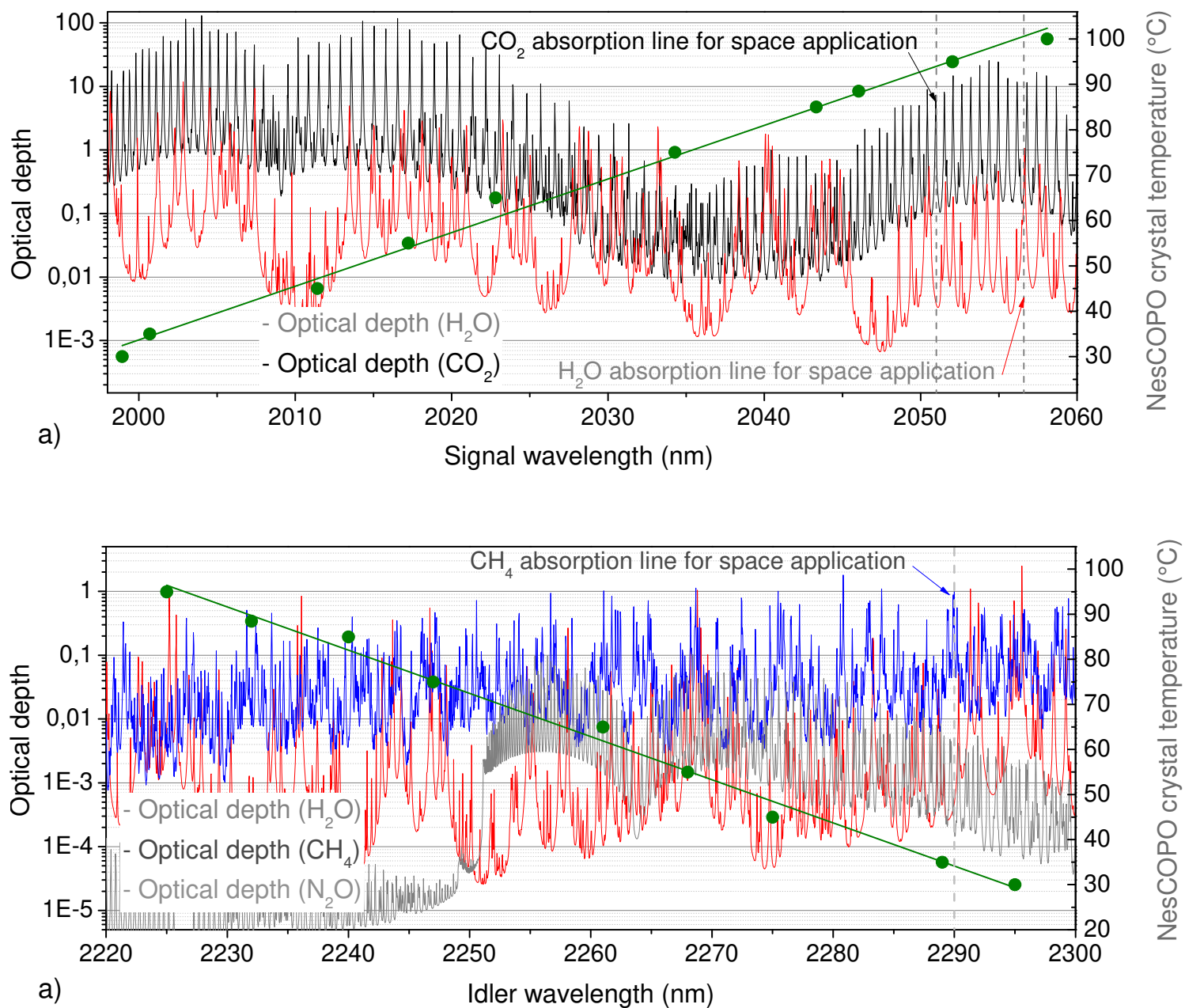

Figure 2. Wavelength range reachable by temperature tuning of the amplified NesCOPO over two adjacent QPM periods: (a) signal wavelength emitted with the $14.369 \mu \mathrm{m}$ QPM period, used for $\mathrm{H}_{2} \mathrm{O}$ and $\mathrm{CO}_{2}$ measurements; (b) idler wavelength with the $14.38 \mu \mathrm{m}$ QPM period, used for $\mathrm{CH}_{4}$, and corresponding greenhouse gases spectral lines (dots: experimental data, lines: optical depths calculated using HITRAN 2012 database for 410 ppm of $\mathrm{CO}_{2}$ (black line), 1.7 ppm of $\mathrm{CH}_{4}$ (blue line), a $50 \%$ ground level hygrometry (red line), and $320 \mathrm{ppb}$ of $\mathrm{N}_{2} \mathrm{O}$ over a $65 \mathrm{~km}$ vertical path, vertical dashed lines: absorption lines for space applications).

The main absorption lines of interest for spaceborne DIAL applications in the $2 \mu \mathrm{m}$ range are thus covered by a single emitter for all the three species ${ }^{1,2}$. To our best knowledge, this leads to the first emitter developed so far, capable to address the three main greenhouse gases $\left(\mathrm{CO}_{2}, \mathrm{H}_{2} \mathrm{O}, \mathrm{CH}_{4}\right)$ in the $2 \mu \mathrm{m}$ region. To reduce the switch time from a species to the other from a few minutes to a few seconds, specifically designed PPLN periods should be used for the NesCOPO and OPA, and automatic rotation of the KTP crystals or use of PPKTP crystals implemented for the OPA. 
Then, we investigate the emitter output pulse energy at these wavelengths.

Table 1. Output pulse energies and conversion efficiencies generated by the emitter

\begin{tabular}{|c|c|c|c|c|c|c|c|c|c|}
\hline $\begin{array}{l}\text { Targeted } \\
\text { species }\end{array}$ & $\begin{array}{c}\text { Crystal } \\
\text { temperature }\end{array}$ & $\begin{array}{c}\text { Crystal } \\
\text { QPM period }\end{array}$ & $\begin{array}{l}\text { Wavelength } \\
\text { (nm) }\end{array}$ & $\begin{array}{l}\text { Signal } \\
\text { output } \\
\text { energy }\end{array}$ & $\begin{array}{c}\text { Idler } \\
\text { output } \\
\text { energy }\end{array}$ & $\begin{array}{c}\text { Total output } \\
\text { energy }\end{array}$ & \multicolumn{3}{|c|}{$\begin{array}{c}\text { Optical to optical conversion } \\
\text { efficiency } \\
\text { (Total / Signal / Idler) }\end{array}$} \\
\hline $\mathrm{CO}_{2}$ & $88.5^{\circ} \mathrm{C}$ & $14.369 \mu \mathrm{m}$ & $\lambda_{\mathrm{s}}=2050.97$ & $20 \mathrm{~mJ}$ & $17 \mathrm{~mJ}$ & $37 \mathrm{~mJ}$ & $37 \%$ & $20 \%$ & $17 \%$ \\
\hline $\mathrm{H}_{2} \mathrm{O}$ & $94.5^{\circ} \mathrm{C}$ & $14.369 \mu \mathrm{m}$ & $\lambda_{\mathrm{s}}=2056.64$ & $20 \mathrm{~mJ}$ & $16 \mathrm{~mJ}$ & $36 \mathrm{~mJ}$ & $36 \%$ & $20 \%$ & $16 \%$ \\
\hline $\mathrm{CH}_{4}$ & $30^{\circ} \mathrm{C}$ & $14.38 \mu \mathrm{m}$ & $\lambda_{\mathrm{i}}=2.29 \mu \mathrm{m}$ & $20 \mathrm{~mJ}$ & $17 \mathrm{~mJ}$ & $37 \mathrm{~mJ}$ & $37 \%$ & $20 \%$ & $17 \%$ \\
\hline
\end{tabular}

A typical $37 \%$ pump depletion after the KTP amplification stage is measured. The typical extracted signal energy at $2.05 \mu \mathrm{m}$ is $20 \mathrm{~mJ}$ for $100 \mathrm{~mJ}$ of incident pump energy on the KTP amplifier (see Table 1).

We also verified that a high beam quality is maintained thanks to the idler filtering mirror inserted between crystal 3 and crystal 4, which limits back-conversion. Such an idler filtering indeed reduces saturation and its effects on the beam quality ${ }^{14}$. The signal beam propagation factor was measured to be $\mathrm{M}^{2}<1.5$ for both vertical and horizontal directions.

The obtained energies are very close to the necessary $20 \mathrm{~mJ}$ for direct detection of $\mathrm{CH}_{4}$ from space ${ }^{1}$.

Adaption of the MOPA setup to pump it with laser delivering four-time higher pulse energy would be sufficient to scale it up to the required energy for IPDIAL monitoring of $\mathrm{CO}_{2}$ from space in the $2 \mu \mathrm{m}$ range ${ }^{1}$. The actual $20 \mathrm{~mJ}$ signal emitted energy at $2.05 \mu \mathrm{m}$ is nonetheless sufficient to implement our emitter for $\mathrm{CO}_{2}$ ground based DIAL measurements ${ }^{15}$.

\section{EMITTER SPECTRAL CHARACTERISTICS AND PERFORMANCES}

The spectral properties of the emitter are a key parameter to achieve a precise and stable measurement from space.

Here, we investigate: i) the frequency stability of the optical source, ii) the linewidth of the emitted radiation.

To assess the shot-by-shot signal frequency stability of the emitter, the signal wave is measured after second harmonic generation, using a wavemeter (WSU 10 High Finesse) with an operating range up to $1.1 \mu \mathrm{m}$. This instrument's performances were first characterized using an optical source locked on a $\mathrm{Rb}$ atomic transition at $780 \mathrm{~nm}$, showing that the instrument resolution is sufficient to measure the frequency stability of our setup to sub-MHz levels over $10 \mathrm{~s}$. As shown in Figure 3, the signal frequency stability for the locked OPO is better than $1 \mathrm{MHz}$ rms, over 10 seconds. The short term $(<1 \mathrm{~s})$ frequency fluctuations are partially attributed to the residual electronic noise of the NesCOPO piezoelectric transducers driver, measured to lead to frequency fluctuations of around $2 \mathrm{MHz} \mathrm{rms}$, to the Nd:YAG laser frequency fluctuations, and to thermo-mechanical fluctuations. This short term stability could be further improved using better opto-mechanical design and lower-noise piezoelectric transducers, which is under investigation in the frame of an ongoing study. With active control of the position of mirror M1 to correct the drift of the emitted signal frequency, we were able to maintain the emitted signal frequency with a sub-MHz stability for a $10 \mathrm{~s}$ averaging time, taking into account the error signal given by the wavemeter (see figure 3). Future developments on this point include: i) the improvement of the thermo-mechanical design to reach a stability better than $0.2 \mathrm{MHz}$ rms over $10 \mathrm{~s}$; ii) the control of the MOPA output purity to prevent from side-mode hops in case of important pump fluctuations after several minutes; iii) active frequency tuning comprising continuous tuning to lock the emitted frequency a few $\mathrm{GHz}$ away from the line centers and then mode-hop tuning by Vernier frequency sampling to perform multi-line sampling of the targeted gases, thus generating several $\mathrm{ON}$ and $\mathrm{OFF}$ wavelengths at the exact wavelengths required for spaceborne IPDIAL applications. 


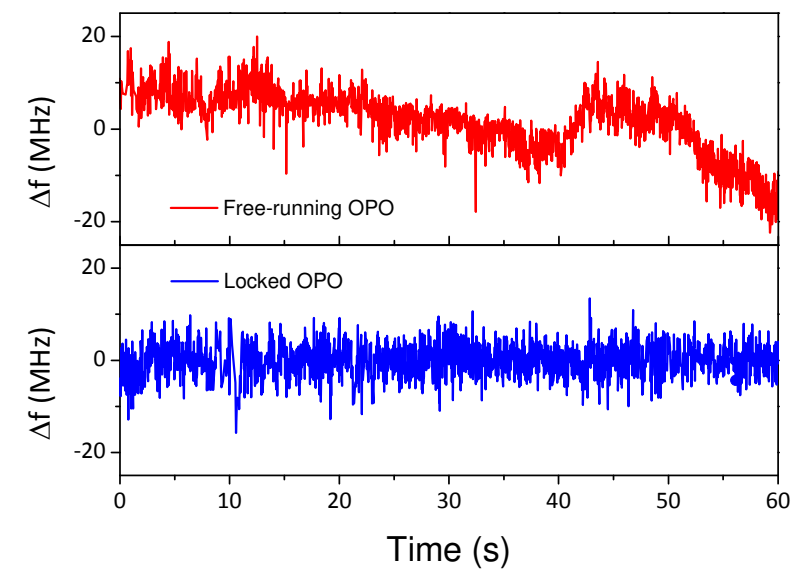

(a)

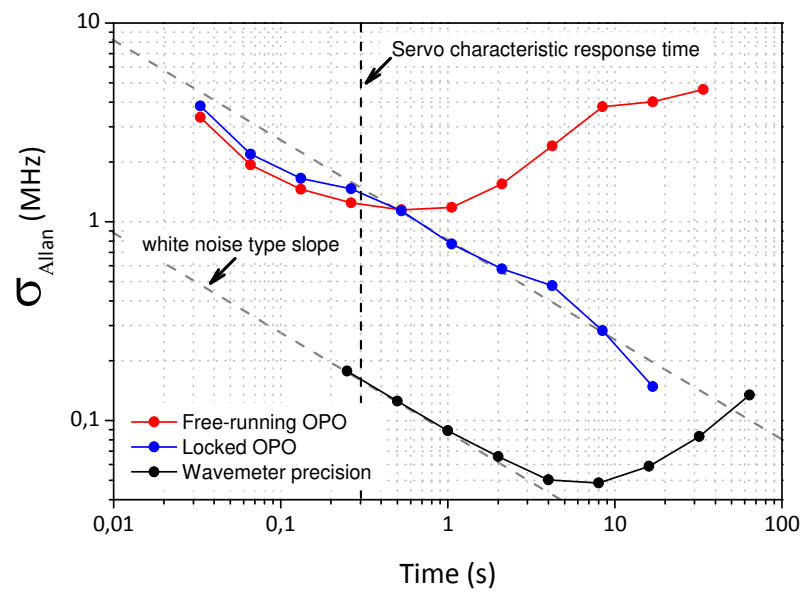

(b)

Figure 3. Frequency fluctuations around central value over a minute of a free running NesCOPO (top graph) and a frequency locked NesCOPO (bottom graph) using the error signal provided by a high finesse wavemeter (a). Allan deviation of the signal frequency $\sigma(\mathrm{MHz})$ emitted by our MOPA setup as a function of the integration time $\tau(\mathrm{s})$, with active control (closed loop curve) of mirror M1 position.

The side-mode suppression ratio and the mean linewidth over $10 \mathrm{~s}$ were also measured at the output of the emitter, by recording the beat-note between the emitter signal and a single frequency $2.05 \mu \mathrm{m}$ diode laser (Nanoplus), detected by a fast InGaAs photodiode (12 GHz bandwidth). The DFB diode laser at $2051 \mathrm{~nm}$ has an estimated linewidth better than $1 \mathrm{MHz}$ and is locked on the $\mathrm{R} 30$ line of $\mathrm{CO}_{2}$. The frequency lock-in is performed with current modulation of the diode laser at $10 \mathrm{kHz}$ in order to provide wavelength modulation through the $\mathrm{CO}_{2}$ line. The absorption signal is retrieved at the output of a multipass-gas cell (absorption path $=30 \mathrm{~m}$ ) filled with low pressure pure $\mathrm{CO}_{2}(5$ mbar). The absorption signal is then demodulated and fed back to the diode laser current with a PI (Proportional Integrator) lock-in amplifier.

The signal output of our emitter is partially coupled to a single mode fiber and mixed with the diode laser radiation on a fast InGaAs photodetector with a $12 \mathrm{GHz}$ detection bandwidth. A fast oscilloscope (13 GHz bandwidth) and a broadband spectrum analyzer enable the visualization of the beat note signal between the diode laser and the parametric source in the time (Figure 4) and spectral domains (Figure 5).

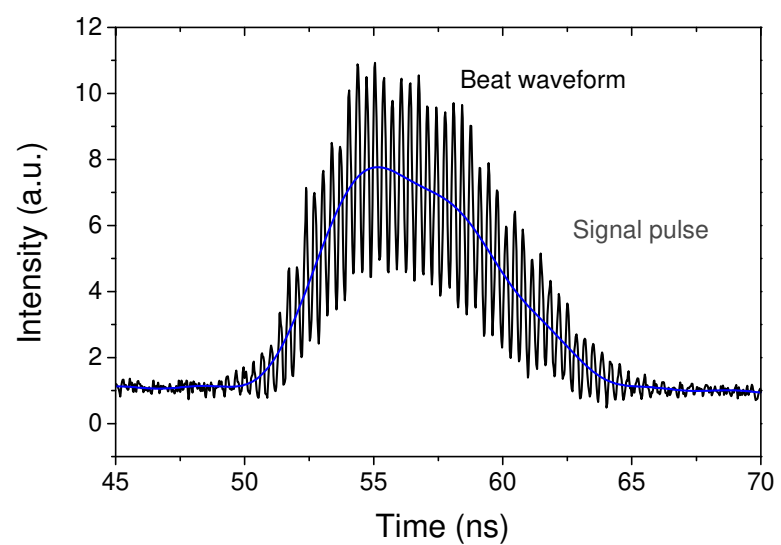

Figure 4. Instantaneous beat note between output pulses from the emitter and the DFB diode laser at $2051 \mathrm{~nm}$, acquired with a fast oscilloscope (13 GHz bandwidth). 


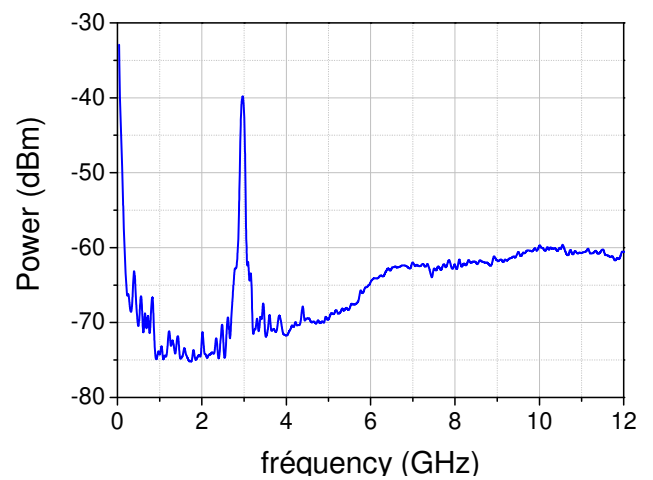

(a)

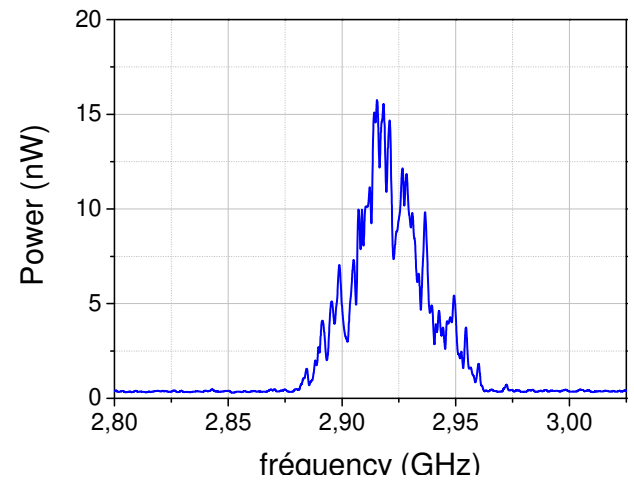

(b)

Figure 5. RF spectrum of the beat-note between a $2.05 \mu \mathrm{m}$ laser diode and the signal emitted by the MOPA system, recorded on a fast InGaAs photodiode and an electrical spectrum analyzer a) over the full detection bandwidth (12 GHz) b) centered on the beat frequency. In this case the central beat frequency is around $2.92 \mathrm{GHz}$, and the signals are averaged over $20 \mathrm{~s}$.

The diode laser frequency and the emitter frequency were separated of around $3 \mathrm{GHz}$ during these measurements. As we can see in Figure 5, the beat-note RF spectrum displays a single peak near $3 \mathrm{GHz}$. No additional peaks separated of a few $\mathrm{GHz}$, which could correspond to the NesCOPO free-spectral range, are observed. This thus insures a side-mode suppression ratio better than $20 \mathrm{~dB}$, limited at this time by the noise of the spectrum analyzer. The full width at half maximum of the beat-note line is measured to be in the $60 \mathrm{MHz}$ range. This value corresponds to the convolution of our emitter and the laser diode linewidths, including their respective frequency fluctuations. It thus gives us an upper value of the mean linewidth, which also assesses the high purity of the radiation emitted by our setup. Higher sensitivity and rapidity of these measurements to assess a $>99.98 \%$ purity would require a higher beat-note power. Nevertheless, these measurements clearly show that, with a high purity oscillator and a well-designed amplifier to prevent saturation effects, no line broadening effects were actually observed after amplification.

Finally, we evaluated the evolution of the "instantaneous" frequency during the pulse on a nanosecond timescale. To analyze the potential frequency chirps, we employed an optical heterodyne method which has been largely developed and implemented in the field of injection seeded pulsed laser and OPO in order to assess the quality of the injection process $^{16,17,18}$. Figure 6 illustrates a typical beating signal that was used to extract the frequency shifts as well as the envelope of the beat waveform, which corresponds to the signal pulse temporal shape. In our case, the central beat frequency is approximately $900 \mathrm{MHz}$ and the OPO is operating in free-running mode.

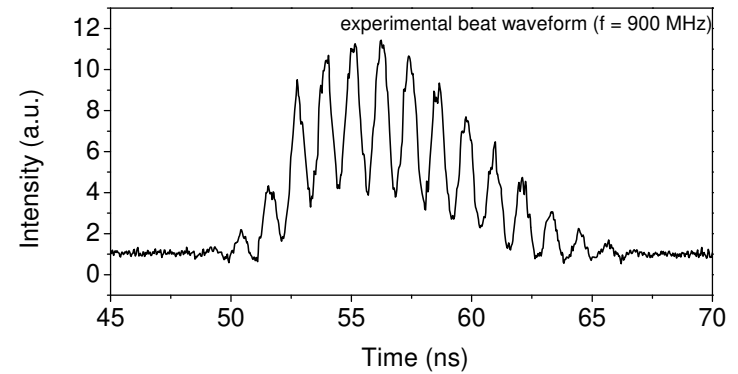

(a)

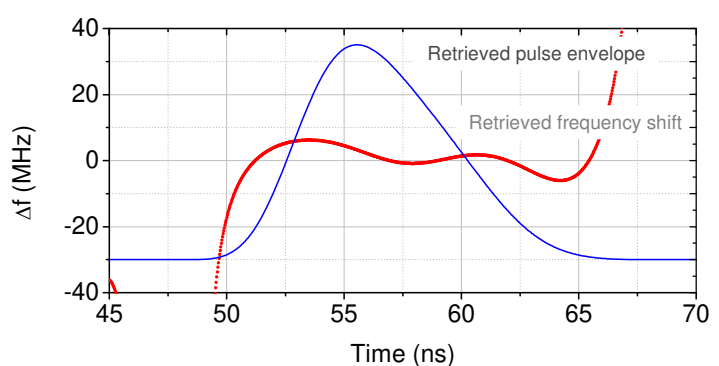

(b)

Figure 6. Optical heterodyne analysis of the "instantaneous" frequency shift inside a single pulse at the output of the amplified NesCOPO parametric source. Beat waveform (a). Retrieved envelope and frequency chirp (b). The overall numerical bandwidth of the analysis is $175 \mathrm{MHz}$.

The calculations and numerical filtering were performed following the protocol reported by Cabaret et al. ${ }^{17}$. As shown in Figure 5(b), the frequency chirp in the vicinity of the pulse maximum intensity is low ( $<10 \mathrm{MHz})$ compared with the mean linewidth measured. These results thus confirm that a good spectral quality can be achieved at the output of the parametric amplifier without significant additional spectral broadening or frequency shifts. 


\section{CONCLUSION}

In conclusion, we have demonstrated the first emitter able to address the $\mathrm{CO}_{2}, \mathrm{CH}_{4}$ and $\mathrm{H}_{2} \mathrm{O}$ lines of interest in the $2 \mu \mathrm{m}$ region for IPDIAL monitoring of atmospheric concentrations from space. This emitter is a step towards multi-species instrument. Future work will first be dedicated to the improvement of the frequency stabilization through improved thermo-mechanical design and tuning scheme. In particular, locking of the emitted frequencies a few $\mathrm{GHz}$ from the line center and shot-by-shot tuning between ON and OFF IPDIAL wavelengths is necessary for DIAL green-house gases monitoring from space, and is currently under investigation. We will also improve the source technical readiness level through proper thermo-optical design and environmental testing, including laser induced damage threshold on critical optics, multi-species multi-line sampling DIAL experiments, and carry out energy scaling up to the $80 \mathrm{~mJ}$ level required for space applications.

This work has been partially supported by contract 115606/00, "Source paramétrique multi-longueurs d'onde pour Lidar DIAL", of the CNES Research and Technology program.

\section{REFERENCES}

[1] G. Ehret, C. Kiemle, M. Wirth, A. Amediek, A. Fix, and S. Houweling, "Space-borne remote sensing of CO2, CH4, and $\mathrm{N} 2 \mathrm{O}$ by integrated path differential absorption lidar: a sensitivity analysis", Appl. Phys. B 90, 593-608 (2008).

[2] J. Caron and Y. Durand, "Operating wavelengths optimization for a spaceborne lidar measuring atmospheric CO2", Appl. Opt. 48, 5413-5422 (2009).

[3] G. J. Koch, J. Y. Beyon, F. Gibert, B. W. Barnes, S. Ismail, M. Petros, P. J. Petzar, J. Yu, E. A. Modlin, K. J. Davis, and U. N. Singh, "Side-line tunable laser transmitter for differential absorption lidar measurements of CO2: design and application to atmospheric measurements," Appl. Opt. 47, 944-956 (2008)

[4] F. Gibert, P. H. Flamant, D. Bruneau, and C. Loth, "Two-micrometer heterodyne differential absorption lidar measurements of the atmospheric CO2 mixing ratio in the boundary layer," Appl. Opt. 45, 4448-4458 (2006)

[5] A.. Fix, C. Büdenbender, M. Wirth, M. Quatrevalet, A. Amediek, C. Kiemle, and G. Ehret, "Optical parametric oscillators and amplifiers for airborne and spaceborne active remote sensing of CO2 and CH4," Proc. SPIE 8182 , 818206 (2011).

[6] D. Sakaizawa, M. Nakajima, Y. Sawa, H. Matsueda, and S. Kawakami, "Ground-based demonstration of a CO2 remote sensor using a $1.57 \mu \mathrm{m}$ differential laser absorption spectrometer with direct detection," J. Appl. Remote Sens. 4, 043548 (2010).

[7] K. Numata, S. Wu, and H. Riris, "Fast-switching methane lidar transmitter based on a seeded optical parametric oscillator," Appl. Phys. B 116, 959-966 (2014).

[8] P. Weibring, H. Edner, and S. Svanberg, "Versatile mobile lidar system for environmental monitoring," Appl. Opt. 42, 3583-3594 (2003)

[9] K. Numata, H. Riris, S. Li, S. Wu, S. R. Kawa, M. Krainak, and J. Abshire, "Ground demonstration of trace gas lidar based on optical parametric amplifier," J. Appl. Remote Sens. 6, 063561 (2012).

[10] B. Hardy, A. Berrou, S. Guilbaud, M. Raybaut, A. Godard, and M. Lefebvre, "Compact, single-frequency, doubly resonant optical parametric oscillator pumped in an achromatic phase-adapted double-pass geometry," Opt. Lett. 36, 678-680 (2011)

[11] B. Hardy, M. Raybaut, J.-B. Dherbecourt, J.-M. Melkonian, A. Godard, A. Mohamed, and M. Lefebvre, "Vernier frequency sampling: a new tuning approach in spectroscopy-application to multi-wavelength integrated path DIAL," Appl. Phys. B 107, 643-647 (2012).

[12] J. Barrientos Barria, A. Dobroc, H. Coudert-Alteirac, M. Raybaut, N. Cézard, J.-B. Dherbecourt, B. Faure, G. Souhaité, J.-M. Melkonian, A. Godard, M. Lefebvre, and J. Pelon, "Simultaneous remote monitoring of atmospheric methane and water vapor using an integrated path DIAL instrument based on a widely tunable optical parametric source," Appl. Phys. B 117, 509-518 (2014).

[13] M. Raybaut, T. Schmid, A. Godard, A. K. Mohamed, M. Lefebvre, F. Marnas, P. Flamant, A. Bohman, P. Geiser, and P. Kaspersen, "High-energy single-longitudinal mode nearly diffraction-limited optical parametric source with $3 \mathrm{MHz}$ frequency stability for CO2 DIAL," Opt. Lett. 34, 2069-2071 (2009)

[14] G. Arisholm, R. Nordseth, and G. Rustad, "Optical parametric master oscillator and power amplifier for efficient conversion of high-energy pulses with high beam quality," Opt. Express 12, 4189-4197 (2004) 
[15] N. Sugimoto, N. Sims, K. Chan, D. K. Killinger, "Eye-safe 2.1- $\mu \mathrm{m}$ Ho lidar for measuring atmospheric density profiles," Opt. Lett. 15, 302-304 (1990)

[16] M. S. Fee, K. Danzmann, and S. Chu, "Optical heterodyne measurement of pulsed lasers: Toward high-precision pulsed spectroscopy" Phys. Rev. A, 45, 4911-4924 (1992).

[17] L. Cabaret and C. Drag, "Highly scannable injection seeded nanosecond Ti:sapphire ring laser" Eur. Phys. J. Appl. Phys., 51, 20702 (2011).

[18] R.T. White, Y. He, B. J. Orr, M. Kono, and K. G. H. Baldwin, "Control of frequency chirp in nanosecond-pulsed laser spectroscopy. 3. Spectrotemporal dynamics of an injection-seeded optical parametric oscillator" J. Opt. Soc. Am. B, 24, 2601-2609 (2007). 